\title{
A Qualitative Exploration of Exercise Among Pulmonary Rehabilitation Participants: Insight From Multiple Sources of Social Influence
}

\author{
Chad SG Witcher PhD, Kerry R McGannon PhD, Paul Hernandez MD, Gail Dechman PhD, \\ Suzanne Ferrier MSc, John C Spence PhD, Ryan E Rhodes PhD, and Chris M Blanchard PhD
}

\begin{abstract}
BACKGROUND: Exercise training within the pulmonary rehabilitation (PR) context is considered the most effective strategy to reduce COPD symptoms. However, participation in PR and continued exercise training following program completion are low. Previous research examined factors related to attendance and adherence, but the knowledge base to date has been limited to quantitative findings that focus solely on participants diagnosed with COPD. In addition to quantitative research, exploring multiple perspectives (eg, PR participants, significant others, staff, and stakeholders) using qualitative research methods opens a window of additional understanding. The goal of this study was to obtain multiple perspectives on PR to gain insight into factors that affect exercise participation among individuals diagnosed with COPD. METHODS: A total of 26 participants were interviewed via telephone, including 8 individuals diagnosed with COPD (4 men and 4 women, mean age of 67 [range of 58-77] y), 4 family members, 11 PR staff, and 3 community stakeholders. RESULTS: Analysis revealed 3 themes: task self-efficacy for exercise, provision of support and encouragement, and perceptions of gender differences. Despite initial concerns, individuals diagnosed with COPD reported becoming more confident during PR and emphasized the importance of being supported by staff. PR staff perceived that men tended to approach exercise in a more eager and aggressive manner compared with women, who were more cautious and hesitant. CONCLUSIONS: In addition to enhancing task self-efficacy, findings suggest that exercise participation and adherence within the PR environment may be improved by adopting a gender-tailored approach. Key words: COPD; rehabilitation; exercise self-efficacy; qualitative; gender. [Respir Care 2015;60(11):1624-1634. () 2015 Daedalus Enterprises]
\end{abstract}

\section{Introduction}

COPD is characterized by progressive and chronic airflow limitation that is not fully reversible and is the third

Dr Witcher is affiliated with the Public Health Program, Faculty of Health Sciences, University of Lethbridge, Lethbridge, Alberta, Canada. Dr McGannon is affiliated with the School of Human Kinetics, Laurentian University, Sudbury, Ontario, Canada. Drs Hernandez and Blanchard are affiliated with the Department of Medicine, and Dr Dechman is affiliated with the School of Physiotherapy, Dalhousie University, Halifax, Nova Scotia, Canada. Ms Ferrier is affiliated with the Cardiovascular Research Unit, Capital Health, Halifax, Nova Scotia, Canada. Dr Spence is affiliated with the Faculty of Physical Education and Recreation, University of Alberta, Edmonton, Alberta, Canada. Dr Rhodes is affiliated with the Behavioural Medicine Laboratory, Faculty of Education, University of Victoria, Victoria, British Columbia, Canada. leading cause of death in the United States ${ }^{1}$ and the fourth leading cause worldwide ${ }^{2}$ and in Canada. ${ }^{3}$ Four percent of Canadian adults 35-79 y of age reported having a physician diagnosis of COPD, although national spirometry data indicated that $13 \%$ of Canadians in this age group had a measured air-flow obstruction on spirometry testing con-

\footnotetext{
This study was supported by a Social Sciences and Humanities Research Council (SSHRC) of Canada operating grant. The authors have disclosed no conflicts of interest.

Correspondence: Chad SG Witcher PhD, Faculty of Health Sciences, University of Lethbridge, 4401 University Drive West, Lethbridge, Alberta T1K 3M4, Canada. E-mail: chad.witcher@uleth.ca.
}

DOI: $10.4187 /$ respcare. 04120 
sistent with COPD $\left(\mathrm{FEV}_{1} / \mathrm{FVC}<0.70\right) .{ }^{4}$ The health-care costs associated with COPD are significant. Among Canadians with ambulatory care-sensitive conditions, individuals diagnosed with COPD accounted for the highest per capita age-standardized hospitalization rate $(96 / 100,000$ population) in 2006-2007.5 The physical challenges for individuals diagnosed with COPD are also significant, including physical limitations in carrying out activities of daily living and reduced health-related quality of life. ${ }^{6}$

Pulmonary rehabilitation (PR) is the standard of care for individuals diagnosed with COPD who remain symptomatic despite bronchodilator therapies. ${ }^{7}$ An important goal of PR is to improve exercise capacity over the course of multiple weeks of exercise training and to reduce the symptoms of COPD, including dyspnea and lack of energy. ${ }^{8}$ Despite the importance of exercise training to COPD, participation in $\mathrm{PR}$ and program completion rates among those who attend PR are low. Previous research indicated that between 8.3 and $49.6 \%$ of referred participants did not attend PR and between 9.7 and $31.8 \%$ of those who began PR failed to complete the program. ${ }^{9}$

Given the vital role of exercise in improving quality of life, ${ }^{10}$ relatively low PR participation rates and poor exercise adherence during and after PR raise a number of concerns, including the exacerbation of symptoms associated with COPD and the costs associated with COPD at the system level (which exceed 40 billion dollars) and individual level (between $\$ 2,700$ and \$5,900/patient annually) in the United States. ${ }^{11}$ Examining the factors that enable or impede exercise participation among individuals diagnosed with COPD can inform future interventions designed to facilitate increased exercise participation: reducing exacerbations, improving quality of life, and reducing individual- and system-level costs associated with COPD.

Factors that may facilitate exercise participation among individuals diagnosed with COPD include personal drivers (eg, self-motivation, desire to improve COPD symptoms) and various personal and professional supports ${ }^{12}$, such as support from peers with a COPD diagnosis. ${ }^{13}$ Salient factors that impede exercise participation include other commitments, health problems, exacerbation of COPD symptoms, perception of exercise as too strenuous, inclement weather, and lack of social support. ${ }^{12}$ Additionally, higher levels of task self-efficacy (ie, confidence that one can manage breathlessness while participating in activities) have been associated with an increase in exercise participation among individuals diagnosed with COPD. ${ }^{14}$

The evidence cited indicates that the knowledge base with respect to exercise by those diagnosed with COPD is growing. However, a number of research gaps remain. Methodologically, the majority of research that has investigated exercise by those diagnosed with COPD has relied upon quantitative measurement and analysis. Although increasing, research informed by additional approaches (eg,

\section{QUICK LOOK}

\section{Current knowledge}

Exercise training as part of a pulmonary rehabilitation (PR) program is an effective strategy to reduce symptoms in patients with COPD. However, participation in $\mathrm{PR}$ and continuing exercise training following program completion is poor. Previous research has focused on factors related to poor adherence in COPD.

\section{What this paper contributes to our knowledge}

In addition to enhancing task self-efficacy, the results suggest that exercise participation and adherence within a PR environment may be improved by adopting a gender-tailored approach.

qualitative) remains an important growth area within the COPD field and may serve to complement quantitative findings. ${ }^{13,15,16}$ Without obtaining in-depth information of this nature, important aspects of exercise and preferences of those diagnosed with COPD may be missed. ${ }^{17}$

Another gap within the literature pertains to studying exercise beyond an individual level and including social influences (eg, spouses, health-care staff) to contextualize individual behavior and experiences. Such inclusion acknowledges the complexity of health behavior change and increases the likelihood of successful intervention development. ${ }^{18}$ Therefore, the purpose of this study was to obtain multiple perspectives (from individuals diagnosed with COPD, family members, PR staff, and community stakeholders) on PR to gain insight into factors that affect exercise participation among individuals diagnosed with COPD. Consistent with this purpose, the following research questions guided the study: (1) What are the beliefs regarding exercise participation among participants diagnosed with COPD? (2) What factors facilitate or restrict exercise participation among those diagnosed with COPD? (3) What are participants' experiences within the PR context? (4) How may multilevel perspectives and experiences inform our understanding of the nature of exercise participation among those diagnosed with COPD?

\section{Methods}

\section{Design}

Five PR programs in Canada ( 2 in Nova Scotia, one in New Brunswick, one in Saskatchewan, and one in British Columbia) provided medically supervised exercise training and patient education to reduce symptoms of COPD; promote behavior modification; and increase self-efficacy, 
exercise capacity, and quality of life. The programs ranged in duration $(6,10$, or 12 weeks), frequency of exercise training sessions ( 2 or 3 times/week), total number of supervised exercise sessions (18, 20, or 24 sessions), and location (community- or hospital-based). Subjects exercised for $1-1.5 \mathrm{~h} / \mathrm{session}$, and each session included aerobic and resistance training. Aerobic exercise training involved progression to achieve $60-80 \%$ of maximum power output for $30 \mathrm{~min}$. Strength training included 2-3 sets of 8-10 repetitions at a moderate-to-high intensity (ie, approximating $50-85 \%$ of maximum). Programs also included formalized patient education sessions on a number of topics, including respiratory anatomy and physiology, pathophysiology of COPD, airway clearance techniques, benefits of exercise, nutrition, medications and devices, smoking cessation, coping strategies, and advanced care planning.

\section{Recruitment}

Individuals Diagnosed With COPD. Recruitment was coordinated in the 5 abovementioned Canadian sites (in the provinces of Nova Scotia, New Brunswick, Saskatchewan, and British Columbia). Specifically, a research assistant contacted participants enrolled in the larger study and asked if they would consent to being contacted regarding participation in the present study at a later date. If consent was given, participants were also asked to forward their contact information to the research assistant. To increase the likelihood of representation across the spectrum of physical activity and disease severity, one eligible male and female subject who provided consent to be approached about participating in an interview were then randomly selected, and their contact information was forwarded to the research coordinator at the central site. The research coordinator then contacted potential participants individually, via telephone, and extended a formal invitation to participate in the present study. A quota sampling strategy ${ }^{19}$ was used in which participants were selected based upon particular eligibility criteria: (1) $\geq 18$ y of age, (2) established COPD (based on chart review), (3) recent completion of the quantitative study, (4) ability to provide informed consent, and (5) ability to read and write in English or French. (Originally, an additional criterion specified that participants must have a significant other who was also willing to participate. However, due to difficulties in recruiting, this criterion was relaxed to being preferred rather than required.)

Family Members. During subject recruitment, the research coordinator asked whether the spouses and/or other family members of potential participants (when applicable) would be interested in participating in the study. If so, they were also contacted by the research coordinator and invited to participate.

PR Staff. A research assistant from each site made initial contact with staff members directly involved with the exercise component of each respective PR program and explained the study. If staff expressed an interest in participating and consented to be contacted regarding future participation, the research assistant collected and forwarded the names and contact information to the research coordinator. The research coordinator then contacted potential participants individually, via telephone, and extended a formal invitation to participate in the study.

Community Stakeholders. Similar to staff member recruitment, each site was responsible for identifying potential stakeholders. Sites, via the research assistant, forwarded the names and contact information to the research coordinator. The research coordinator then contacted potential participants individually, via telephone, and extended a formal invitation to participate in the study.

Refusals. The number of potential participants who refused to be contacted by the research coordinator was not recorded by research assistants. However, all potential participants who consented to be contacted by the research coordinator (and were reachable) agreed to participate in the study. In several cases, potential participants did not respond to invitations extended by the research coordinator via telephone (ie, 2 participants diagnosed with COPD, 2 family members, one staff member, and one community stakeholder); one participant diagnosed with COPD who agreed to participate died before being interviewed.

\section{Participants}

A total of 26 participants were interviewed by the research coordinator via telephone, including 8 patients (4 men and 4 women, mean age of 67 [range of 58-77] y) diagnosed with COPD according to Canadian Thoracic Society criteria $\left(\mathrm{FEV}_{1} / \mathrm{FVC}<0.70\right),{ }^{20} 4$ family members ( 2 men and 2 women), 11 PR staff ( 2 men and 9 women), and 3 community stakeholders ( 2 men and one woman). Of the subjects diagnosed with COPD, 6 were retired, one was on disability leave from work, one did not provide data regarding occupation or retirement status. Two subjects were widowed, 2 never married, and 4 were either married or living with a partner. Subjects diagnosed with COPD reported receiving 10-18 y of formal education.

Family members who participated included 2 spouses, one daughter, and one sister-in-law. PR staff participants ( 2 men and 9 women) included 5 physiotherapists, 2 nurses, one respiratory therapist, one respiratory educator, one exercise therapist, and one rehabilitation assis- 
tant. Stakeholders (2 men and one woman) were in executive and managerial positions within professional health organizations.

\section{Procedures}

Once participants had been recruited into the study, the research coordinator scheduled a telephone interview at a mutually agreeable time. Interviews were $\sim 30 \mathrm{~min}$ long, conducted between October 2011 and February 2013, and based on an open-ended, semistructured interview guide designed by KRM, who has extensive background and expertise in qualitative research methods.

Consistent with qualitative research guidelines for eliciting detailed responses, ${ }^{21}$ interviews with subjects diagnosed with COPD included questions regarding the meaning of exercise (eg, what does being physically active mean to you?), exercise experiences (eg, tell me a story about what exercise is like for you), and facilitators/barriers to exercise (eg, tell me about the things that make it more/less likely you could be physically active). Family members' interviews were similar in structure to those with PR participants, but focused on the perspective of the family member (eg, tell me a story about the specific kinds of things that have prevented your spouse/family member from exercising during PR). Interviews with PR staff included questions regarding the nature of a typical exercise session (eg, tell me about a typical exercise session for a patient), reasons for patient engagement (eg, tell me about the things that make it more/less likely patients are physically active), and suggestions to promote increased exercise adherence (eg, tell me about specific suggestions to make it more likely patients would exercise on a regular basis). Stakeholder interviews included questions regarding reasons why PR participants engaged or did not engage in exercise, existing programs that promote exercise participation, and suggestions to improve exercise adherence. Probes (eg, tell more about that, tell me a story about that experience) were also used to obtain data that were as rich and in-depth as possible.

Digital audio recorders were used for all interviews. The digital audio files produced were then professionally transcribed verbatim. All transcripts were stripped of any personal identifying information, with pseudonyms used to protect participants' identities.

Recruitment and data collection methods for all study participants were approved by the appropriate research ethics board at each site before starting the study. Verbal and/or written consent was obtained from all participants before participation in the interviews.

\section{Data Analysis}

Interview data were subjected to a thematic analysis approach whereby patterns (themes) were identified and constructed through an inductive iterative process for all participants. ${ }^{22}$ To define and label the final themes produced, all interview data were initially broken apart by reading/reviewing each transcript, followed by generating initial codes created to denote and describe chunks of text deemed meaningful/noteworthy. Once all transcripts had been coded in this manner, the analysis progressed toward searching for and identifying preliminary patterns (themes) based upon similar chunks of data across the entire data set. The following example illustrates how themes were identified. During an interview, a participant diagnosed with COPD remarked, "Like I said, [PR] brought me back to a place where I actually-I started, and once I started, I found I could do a little bit more and a little bit more and a little bit more instead of giving up." These lines of text were coded as self-efficacy within the transcript.

Once an initial set of themes had been created, analysis shifted toward identifying broader patterns in the data, that is, establishing the number of themes deemed sufficient to capture the essence of the main patterns contained within the data set, followed by creating a label and description of each. Through this process, themes deemed sufficiently similar to one another were combined. Analysis cycled through waves of code development/refinement and theme development/refinement, guided by constant comparison, ${ }^{23}$ toward the final selection of themes. Once this process was completed across all transcripts, analysis was performed using the same procedures to integrate the findings across each participant level (eg, subject, family member, staff, and stakeholder).

\section{Results}

Data provided by subjects diagnosed with COPD, family members, staff, and stakeholders were organized into and captured by 3 main thematic categories (Table 1): task self-efficacy for exercise, provision of support and encouragement, and perceptions of gender differences. Together, these thematic categories provided further insight into the nature of exercise participation among subjects from multiple perspectives/sources of social influence.

\section{Task Self-Efficacy for Exercise}

The theme of task self-efficacy for exercise refers to the confidence of participants diagnosed with COPD in terms of whether they were increasingly capable of engaging in exercise despite initial concerns of harms such as feelings of breathlessness. ${ }^{24}$ This theme also includes perceptions of family, staff, and stakeholders regarding levels of exercise self-efficacy among participants diagnosed with COPD, that is, others' perceptions of diagnosed participants' confidence to engage in exercise. 
Table 1. Summary of Themes

\begin{tabular}{|c|c|}
\hline Theme & Representative Quotations \\
\hline \multicolumn{2}{|l|}{ Task self-efficacy for exercise } \\
\hline $\begin{array}{l}\text { Confidence of subjects with COPD in terms of whether they were } \\
\text { increasingly capable of engaging in exercise despite initial } \\
\text { concerns of harms, such as feelings of breathlessness }\end{array}$ & $\begin{array}{l}\text { Subject with COPD: "Like I said, [PR] brought me back to a place where } \\
\text { I actually . . could do a little bit more and a little bit more and a little } \\
\text { bit more instead of giving up." }\end{array}$ \\
\hline $\begin{array}{l}\text { Others' perceptions of diagnosed participants' confidence to } \\
\text { engage in exercise }\end{array}$ & $\begin{array}{l}\text { Staff member: "I think fear is the biggest thing when they're first coming } \\
\text { into the program. But while they're in the program, they realize that } \\
\text { they can do it ..." }\end{array}$ \\
\hline \multicolumn{2}{|l|}{ Provision of support and encouragement } \\
\hline $\begin{array}{l}\text { Participants' perceptions of receiving support and encouragement } \\
\text { during exercise from various staff members in PR or providing } \\
\text { support }\end{array}$ & $\begin{array}{l}\text { Subject with COPD: “... they make you feel good about yourself ... } \\
\text { they make you feel like you're accomplishing something ... they were } \\
\text { very encouraging." }\end{array}$ \\
\hline $\begin{array}{l}\text { Staff members' efforts to provide support and encouragement in } \\
\text { PR }\end{array}$ & $\begin{array}{l}\text { Staff member: "... we have them set goals for themselves that are } \\
\text { individual ... and are important to them ... that's something we often } \\
\text { will refer back to as ways of encouraging them to keep up..." }\end{array}$ \\
\hline & $\begin{array}{l}\text { Family member: "To be honest, it wasn't the exercise, it was more the } \\
\text { support ... that was what she took away from it more than anything, is } \\
\text { just having other people, like a support group." }\end{array}$ \\
\hline \multicolumn{2}{|l|}{ Perceptions of gender differences } \\
\hline $\begin{array}{l}\text { Perceptions of staff and stakeholders regarding differences } \\
\text { between men and women in how each group approached } \\
\text { exercise and behaved within the PR setting }\end{array}$ & $\begin{array}{l}\text { Staff member: "With the women, I found I had to kind of encourage } \\
\text { them a little bit more, whereas with the men ... some guys would } \\
\text { really want to bump up the treadmill ... Some of the guys would just } \\
\text { want to just go work really hard, whereas women were kind of a little } \\
\text { bit the opposite. So I found that they would need a bit more coaxing } \\
\text { and a bit more support ... [Women] didn't tend to take any risks, } \\
\text { whereas the men with the weights and stuff, like I said, they would } \\
\text { kind of try to add more weights." }\end{array}$ \\
\hline
\end{tabular}

$\overline{\mathrm{PR}}=$ pulmonary rehabilitation

Several subjects diagnosed with COPD indicated that their experiences during PR increased their task self-efficacy for exercise. As a result, the participants' realized personal abilities to engage in various types of exercise were greater than expected. For example, Anna indicated that PR "brought me back to a place where I actually ... could do a little bit more and a little bit more and a little bit more instead of giving up," compared with before PR, "giving up and saying, 'well, I can't do this ... the heck with that, I'm not doing that anymore." Hank also commented on his increased confidence to perform exercise during PR, specifically referencing the supportive nature of the program's staff:

In the program (and the instructors also encouraged me to do it), I was always trying to do more than I had done previously ... I was trying to push the envelope .... and found that I was able to do it.

Similarly, Gina also contextualized her comments regarding her increased confidence by referencing the supportive PR staff:

Well, first of all, when you're under the guidance of professional people and they can tell you what your limits are ... I was quite shocked at what I couldn't do as opposed to what I could do . . . it was actually sort of a wake-up call I think . . . it sort of taught me that I never pushed myself as hard as I could push myself.

These comments are consistent with additional feedback by staff members, who also referred to the importance of fostering increased self-efficacy within the program. For example, Karen remarked:

... many [PR participants] are very anxious about exercise. And so by coming for the 3 months and learning that, "I can walk 10 min and I'm not going to die" or "I'm not going to have an exacerbation," they all contribute to their self-efficacy so they can feel more confident about exercising.

Staff also commented on the improvements observed with respect to task self-efficacy in PR. For instance, Bob said:

I think fear is the biggest thing when they're first coming into the program. But while they're in the program, they realize that they can do it, and do it 
slowly starting off and then gradually increase their time and tolerance for exercise ... once they're in the program a little while and they realize they can do it and it really does help with their breathing and their stamina, then they want to exercise.

Staff indicated that anxiety and fear regarding exercise were significant barriers to fostering task self-efficacy for exercise among PR participants, and comments made by PR participants appeared to confirm this interpretation. For example, as Anna succinctly articulated, "It really changed my life when I went [to PR] because I was basically sitting around the house day after day afraid to move." Similarly, Gina spoke about being:

... very nervous about exercising until I did the rehab class. That was just a period you go through of apprehension, I think, when you're first diagnosed ... once you get over the fear of not being able to breathe if you're exercising then you're off and running ...

Referring to a conversation with a former patient post-PR, Judy, a staff member, provided an example of one participant who appeared to be "off and running" and no longer fearful or anxious:

I did speak with one woman about exercise at the end of the program, and she was saying it has really improved her confidence and that's what's motivating her to continue in the future ... she's really enjoying the benefits of not only having better health but also having a better sense of self and confidence.

Similarly, a spouse of one of the subjects spoke about how she increased her task self-efficacy for exercise:

[Exercise is] something that she has never done. So that's why this class is important. Because ... I think when you never do something, you just don't even think you can.

This comment, in addition to those made by PR participants and staff, illustrate self-efficacy's role in exercise participation during and following PR and reveal how PR programs and staff members are working to improve the task self-efficacy for exercise of participants.

\section{Support and Encouragement}

The theme support and encouragement refers to participants' perceptions of receiving support and encouragement during exercise from various staff members in PR, providing support to participants, or support staff's efforts to provide support and encouragement in PR. Quotations in the previous theme highlight the importance of the support and encouragement provided by PR staff in terms of increasing participants' task self-efficacy for exercise and exercise engagement. The perceived importance of encouragement was also made clear through the perspectives of the PR staff. For instance, Karen explained:

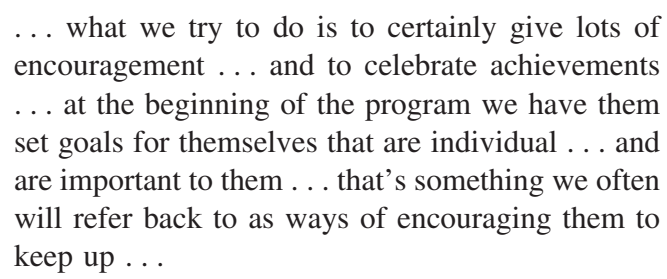

Susan also discussed her approach at the onset of PR:

\begin{abstract}
If you bring them in the first day and just punish them, I don't think you'll see them again. You have to let them feel good about themselves ... there's subtle little positive reinforcement things you do with [participants] while they're exercising"You're doing a good job. You obviously know what you're doing on this. Good choice for using this." You know, little things like that ...
\end{abstract}

From there, as Bob described:

... once we assure them that they're able to do it ... do it slowly and do it correctly, then they overcome that fear and know that they can do it ... they are more apt to do more exercise at home. And they are quite proud of it too ... some of them will come in and say, "you know, I walked up these stairs to my apartment today and had no problem with breathing." That gives them a little bit more incentive to get out and move a little bit more.

This general approach to PR taken by staff was not lost on subjects and fostered feelings of trust and respect. For example, Anna explained:

... they make you feel good about yourself ... they
make you feel like you're accomplishing something
$\ldots$ they were very encouraging. And I think every-
body knew that they were there to help us ... [the
staff] are watching you. You know, you're not go-
ing to pass out or you're not going to cave or any-
thing.

Chuck summarized his experiences this way:

Instead of telling us, you know, "your breathing is lousy because ..." they would say, "Well, your breathing is bad because, but, if you do this with us ..." With us, not because of us ... and that part 
sticks. Because they gave respect, they'd get respect. So respect was given by everybody in the program, and they got respect in return.

PR staff and stakeholders also perceived that the social connectedness of subjects within the PR program played an important supportive and motivational role for participants. As Karen, a staff member, explained:

I think the group setting is motivating, as opposed to trying to implement something and doing it on your own. I think the fact that they have colleagues, so to speak, that they're working with on a regular basis, they get to know them. Because of the way our program is set up, it's done as a cohort. So they come as a group, and they go through the whole program as a group. And I think that's a bit of an advantage when it comes to establishing relationships among the participants, providing support to each other. You know, if one of them gets sick, they're, "Where is so and so?" That sort of thing. And welcoming them back when they do come back, that sort of thing. So those are the things we really try to emphasize, so that they recognize that participation is making a difference.

Similarly, Wayne, a stakeholder, discussed the supportive nature created by the social aspect of PR:

\begin{abstract}
What keeps people is the social side, the fun side, meeting friends, what happens as a result of being involved in a sport or physical activity. And I don't think the difference is very much when it comes to pulmonary rehab... oftentimes it's being a part of a group, the social aspect of it, the welcome, a feeling of belonging.
\end{abstract}

In addition to comments made by PR participants, staff, and stakeholders regarding the supportive nature of PR, a family member also emphasized the social nature of PR for his spouse in particular. When asked what he thought she enjoyed about PR, Tom responded:

To be honest, it wasn't the exercise, it was more the support, like listening to other people's stories. Apparently they had sessions where people just sit around and talk about how they deal with things and cope. And that was what she took away from it more than anything, is just having other people, like a support group. More listening how other people coped with only being able to do so much or do so little. And you know, I really think that that's what she embraced in the whole process ... she really embraced the whole support system. Like she really did. That was something that she really embraced. Because really, she has no one to talk to. It's hard for her to talk to the family about it because we all know that her smoking got her there. So like everybody is so derogatory toward, you know, "Well, you got yourself there," kind of thing, and, "you wouldn't stop smoking." So you know, probably the people she gets to talk to in there don't harp at her. You know, they talk to her about what's going on, with how she's feeling today. Do you know what I mean?

The supportive nature of PR and its importance were captured by subjects diagnosed with COPD, family, staff, and stakeholders.

\section{Perceptions of Gender Differences}

The third theme of perceptions of gender differences refers to perceptions of staff and stakeholders regarding differences between men and women in how each group approached exercise and behaved within the PR setting. Behaviors were largely viewed along gender lines, that is, men were seen as similar to one another and acted a certain way within the PR environment, whereas women were viewed as similar to one another and acted in ways that were distinct from the men in the PR environment.

Staff and stakeholders did not perceive any gender differences with respect to PR participation or exercise behavior during PR. The following response by Tina represents a common response when PR staff were asked about gender differences: "I wouldn't say that there was any difference between male and female. We just take each person as an individual regardless of their gender." Similarly, Rick stated, "I don't see why they should be different." Despite comments of this nature, a more in-depth analysis of additional interviews with staff members suggested that they perceived differences between male and female PR participants, particularly with respect to approach to exercise. These perceived differences affected the approach that staff members took with PR participants. For example, as Judy explained:

With the women, I found I had to kind of encourage
them a little bit more, whereas with the men ...
some guys would really want to bump up the tread-
mill . . . Some of the guys would just want to just go
work really hard, whereas women were kind of a
little bit the opposite. So I found that they would
need a bit more coaxing and a bit more support...
[Women] didn't tend to take any risks, whereas the
men with the weights and stuff, like I said, they
would kind of try to add more weights.

Another staff member, Christine, provided an explanation as to why such a difference between men and women may exist: 
... of this older population of women, I've run into several who have never exercised a day in their life ... it's not been a part of their lifestyle to go to the gym. So other than just walking, many of them will have never exercised. So I suppose there's a steeper learning curve for them, and we might have to be [more] instructional and intentional with the women than we are with the men.

The view that women's lack of exercise experience and familiarity may affect exercise participation was consistent with a subject perspective. For instance, Anna explained:

Okay, exercise. Well, to me exercise, well ... I'm not a gym person, and I'm not, you know, like heading out to the gym and working out in the gym. That's not my thing . . . I like to walk, and I like to skate, things like that. Yes, that would be my idea of exercise. Like, not weightlifting or anything like that. I was never into that type of thing.

The notion that male participants took a more aggressive approach to exercise, which was inherently and naturally part of being a man, was also supported by comments made by a male subject diagnosed with COPD. Based on his experiences in PR, Hank explained:

I know that I'm very competitive. And in the program, I was always trying to do more than I had done previously. And you know, I went from 4 to $6 \%$. I went up to $10 \%$ slope. And I was always trying to push the envelope sort of thing.

Staff also highlighted and reinforced a gender difference with respect to social interactions. For example, Judy remarked:

I think more so with the women, there seems to be a strong kind of social aspect, kind of being open to meeting other people that are in a similar condition. And so I think that the psychosocial component is quite important for women.

Similarly, Christine said:

In terms of continuing, one of the things that motivates them is being able to find a group or maybe having made friends with someone in the class who is now going to continue exercising. So the social aspect of finding a buddy or a partner that they can exercise with, I think that's more a factor for women than it is for the men.

\section{Discussion}

Data analysis resulted in the construction of 3 specific but overarching thematic categories. The first category, task self-efficacy for exercise, described PR participants' confidence that they were increasingly capable of engaging in exercise despite initial concerns of harms (eg, breathlessness). With respect to participants diagnosed with COPD, task self-efficacy for exercise appeared to improve as PR progressed. Although initially underestimating their capabilities, participants described coming to the realization that they were capable of performing PR exercises despite initial concerns about exertion and exacerbation of COPD symptoms. The importance of task self-efficacy has been reported previously in other studies in cardiac rehabilitation and PR populations. ${ }^{14,25}$ Our qualitative findings extend the quantitative measurement and assessment of task self-efficacy as a construct to provide additional insight into the context of task self-efficacy for exercise from the perspectives of both individual participants and PR staff during PR. Furthermore, other studies that reported the potential importance of self-efficacy in the COPD context have operationalized the construct inconsistently or have reduced qualitative data regarding a participant's confidence to exercise to a dichotomous yes/no assessment. ${ }^{14}$ The former case makes comparisons across studies difficult. The latter case limits contextual understanding.

In this study, any potential improvement in task selfefficacy for exercise was often impeded by a subject's initial reluctance to exercise due to fears or apprehension associated with exertion and exacerbation of COPD symptoms. This finding has also been reported in the literature on older adults ${ }^{26,27}$ and cardiac rehabilitation, ${ }^{28}$ where participants expressed concerns regarding exercise as potentially harmful by causing breathlessness (ie, negative outcome expectations). Along with mastery experience, other sources of self-efficacy such as vicarious experience, verbal persuasion, and physiological state would be important to consider in this context.

With respect to the PR programs in this study, staff members were aware of participants' initial fears and anxiety regarding initiating exercise and acknowledged the importance of fostering task self-efficacy for exercise during PR with the intent to address participants' fear and anxiety regarding exertion. These perspectives appear novel, as it is currently unclear within the COPD literature whether and to what extent staff members specifically address task self-efficacy for exercise in PR participants and accommodate negative outcome expectations (eg, fears and concerns) regarding exercise participation. However, by providing support and encouragement in PR, staff members played an important role in reducing the initial fear and anxiety regarding exercise engagement via verbal persuasion ${ }^{29,30}$ with respect to participants' progress, encour- 
aging them to stick with it and reminding participants that the exercise requirements were within their capabilities. Consistent with previous research regarding social support, ${ }^{25}$ the supportive nature of the PR environment was confirmed by PR participants who expressed appreciation for the encouragement of staff members and acknowledged their role in reaching individual goals for PR.

Family, staff, and stakeholders also recognized the importance of social cohesion within PR and, more specifically, the support provided on an individual-to-individual basis by PR participants to enhance feelings of safety and security. The importance of the supportive nature of PR programs is consistent with another qualitative study that explored long-term maintenance of exercise among individuals diagnosed with $\mathrm{COPD}^{15}$ and research regarding social support and exercise maintenance in COPD. ${ }^{31}$ The results from this study make a unique contribution to the literature by further demonstrating the importance of support beyond peers to include support from PR staff.

Although staff members indicated the importance of treating men and women alike in PR, other comments suggested that men and women may have been treated differently. Differential treatment appears to be an appropriate strategy according to recent reviews examining the role of sex in health outcomes in PR. ${ }^{32,33}$ In this study, several staff members discussed women's apprehension regarding exercise and the need for more encouragement to initiate exercise within PR, which was viewed as being different from most men. In contrast, several staff members indicated that men were more likely to approach exercise in an aggressive manner (ie, initiate exercise at relative high intensities with reckless abandon). Additionally, PR staff members speculated that social support may be more important for female participants and less important for male participants in terms of PR adherence. In addition to the PR literature, as noted, sex differences in exercise have been identified among nonclinical populations as well, including Canadian adolescents, ${ }^{34}$ American adults, ${ }^{35,36}$ and older adult Canadians ${ }^{37}$, each demonstrating higher levels among males versus females. Therefore, treating men and women differently within PR appears to be justified.

Despite evidence that supports treating men and women in PR differently, examining sex and gender as social constructions fosters additional understanding of our theme perceptions of gender differences. This more critical type of examination views gender as dynamic rather than as a biological given, referring to roles, behaviors, and attributes considered appropriate for men and women depending on the social and cultural discourses made available to them, often via various social interchanges. ${ }^{38}$ When interpreted through a social constructionist lens, the notions that men prefer certain types of exercise and do not need social support and that women prefer less intense exercise and more social support may be reinforced by various social agents within the PR setting. In turn, certain limiting beliefs and behaviors for men versus women may be circulated, which may have negative implications for individual participant experiences, exercise, and health outcomes. ${ }^{33}$ Therefore, although we acknowledge that sex differences among men and women within PR exist, we caution against ascribing seemingly male or female characteristics to all men or all women in PR. Research in clinical settings outside of PR (eg, cardiac rehabilitation) further highlights the usefulness of considering gender as socially constructed. In this regard, health-care workers' beliefs that men prefer exercise and women do not have shown that women may receive less support and/or exercise referrals ${ }^{39}$ or that both sexes do not receive the type and quality of support needed. ${ }^{40}$ Although themes related to the gendered (ie, socially constructed) ways in which men and women approach exercise have also been explored extensively in nonclinical populations, ${ }^{38,41}$ this topic has not received research attention within the PR setting to date and is an important avenue for future research within the rehabilitation context.

\section{Strengths and Limitations}

This study had several strengths and made unique contributions to the field. Moving beyond considering only perspectives of individuals, this study has the potential to inform future research in the PR area in a more comprehensive way by acknowledging various social influences (eg, patient, family, staff, and stakeholder) that may impact and explain initiation and continued exercise behavior among PR participants. Future interventions informed by multiple perspectives have an improved likelihood of success compared with individual-level approaches. ${ }^{18,25}$ Another strength of this study was its use of qualitative data to gain access to difficult (if not impossible) to glean data; few studies ${ }^{16,42}$ have undertaken qualitative research to explore issues affecting subjects diagnosed with COPD. In particular, our findings highlight the potential importance and complexity of gender-tailored approaches within PR.

An additional strength of this study was related to participant recruitment: existing relationships with other PR programs allowed for representation of multiple perspectives across 5 Canadian sites and 4 provinces. Although a multiple-site approach allowed for representation across Canada, the logistics of conducting interviews from the home was challenging (eg, we were unable to conduct follow-up interviews once the initial data collection/analysis phase was completed). Follow-up interviews may have advanced analysis beyond description and contributed further to the identification of other thematic categories. The data collected are also limited in some ways. Specifically, we are unable to speculate regarding the relevance of these data to the experiences and perceptions of others diag- 
nosed with COPD or associated with PR in programs located in different geographical regions in Canada or in other countries. That said, the point of qualitative research methodologies and methods is not to generalize, but rather to learn more about a phenomenon or topic in-depth, and thus as noted, this so-called limitation is also a strength of our study.

\section{Future Research}

A number of questions are worthy of future investigation. For example, with respect to PR programs in Canada, the United States, and other countries, what standards or policies exist to guide exercise adherence? Should approaches to exercise adherence among PR participants vary according to sex? Future studies should investigate answers to these questions. As mentioned previously, there is also a need for future studies to investigate issues related to exercise participation and adherence from alternative paradigms/perspectives (eg, social constructionism) via the collection and analysis of qualitative data. In addition, studies that adopt a mixed-method design (ie, a combination of quantitative and qualitative methods) may provide flexibility to respond to novel and complex research questions within the same study.

\section{Conclusions}

Our findings provide insight into exercise participation and experiences in PR by providing descriptive detailed accounts of PR participants, family members, PR staff, and stakeholders. In particular, PR participants reported increasing their task self-efficacy for exercise during PR. To facilitate this process, PR staff members created an environment in which participants were supported and encouraged to gradually increase their activity in a variety of progressive exercises during PR. A novel finding that requires further exploration is that PR staff members did not indicate that the approach taken in PR should change based upon sex, despite other comments suggesting that men and women appear to approach exercise in PR differently.

Qualitative studies such as these allow participants to describe their perceptions and experiences in an openended manner, thus enriching our understanding, more generally, of what it means to live with a COPD diagnosis and, more specifically, of how we may improve PR for better exercise adherence. Furthermore, moving beyond an individual perspective (the patient level) by including the perspectives and experiences of family members, PR staff, and stakeholders advances the field by contextualizing PR experiences and perceptions. Conceptualizing exercise behavior within the PR setting in this manner acknowledges the complexity of exercise participation and adherence in this population, potentially leading to improved under- standing of how to maintain exercise participation among those diagnosed with COPD during and after PR.

\section{REFERENCES}

1. Hoyert DL, Xu J. Deaths: preliminary data for 2011. Natl. Vital Stat Rep 2012;61(6):1-52.

2. World Health Organization. The top 10 causes of death. Fact Sheet No. 310. Updated 2014. http://who.int/mediacentre/factsheets/fs310/en/. Accessed February 11, 2015.

3. Statistics Canada. Leading causes of death, total population, by age group and sex, Canada. CANSIM Table 102-0561. Updated 2014. http://www5.statcan.gc.ca/cansim/a05?lang=eng\&id=1020561. Accessed February 11, 2015.

4. Statistics Canada. Chronic obstructive pulmonary disease in Canadians, 2009 to 2011. Health Fact Sheet 82-625-X, 2012. http://www.statcan.gc.ca/pub/82-625-x/2012001/article/11709-eng.htm. Accessed February 11, 2015.

5. Canadian Institute for Health Information. Health Indicators 2008. Ottawa, Ontario, Canada: CIHI; 2008.

6. Reardon JZ, Lareau SC, ZuWallack R. Functional status and quality of life in chronic obstructive pulmonary disease. Am J Med 2006; 119(10 Suppl 1):32-37.

7. Marciniuk DD, Brooks D, Butcher S, Debigare R, Dechman G, Ford $\mathrm{G}$, et al. Optimizing pulmonary rehabilitation in chronic obstructive pulmonary disease - practical issues: a Canadian Thoracic Society Clinical Practice Guideline. Can Respir J 2010;17(4):159-168.

8. Ribeiro F, Thériault M-E, Debigaré R, Maltais F. Should all patients with COPD be exercise trained? J Appl Physiol 2013;114(9):13001308 .

9. Keating A, Lee A, Holland AE. What prevents people with chronic obstructive pulmonary disease from attending pulmonary rehabilitation? A systematic review. Chron Respir Dis 2011;8(2):89-99.

10. Lacasse Y, Martin S, Lasserson TJ, Goldstein RS. Meta-analysis of respiratory rehabilitation in chronic obstructive pulmonary disease. A Cochrane systematic review. Eura Medicophys 2007;43(4):475485.

11. Foster TS, Miller JD, Marton JP, Caloyeras JP, Russell MW, Menzin J. Assessment of the economic burden of COPD in the U.S.: a review and synthesis of the literature. COPD 2006;3(4):211-218.

12. Thorpe O, Johnston K, Kumar S. Barriers and enablers to physical activity participation in patients with COPD: a systematic review. J Cardiopulm Rehabil Prev 2012;32(6):359-369.

13. Hellem E, Bruusgaard KA, Bergland A. Exercise maintenance: COPD patients' perception and perspectives on elements of success in sustaining long-term exercise. Physiother Theory Pract 2012;28(3):206220.

14. Bentsen SB, Wentzel-Larsen T, Henriksen AH, Rokne B, Wahl AK. Self-efficacy as a predictor of improvement in health status and overall quality of life in pulmonary rehabilitation —an exploratory study. Patient Educ Couns 2010;81(1):5-13.

15. Panos RJ, Krywkowski-Mohn SM, Sherman SN, Lach LA. Patient reported determinants of health: a qualitative analysis of veterans with chronic obstructive pulmonary disease. COPD 2013;10(3):333347.

16. Wortz K, Cade A, Menard JR, Lurie S, Lykens K, Bae S, et al. A qualitative study of patients' goals and expectations for self-management of COPD. Prim Care Respir J 2012;21(4):384-391.

17. Hartman JE, ten Hacken NHT, Boezen HM, de Greef MHG. Selfefficacy for physical activity and insight into its benefits are modifiable factors associated with physical activity in people with COPD: a mixed-methods study. J Physiother 2013;59(2):117-124. 


\section{EXERCiSe AmOng PR PARTICIPANTS}

18. Emmons KM. Health behaviors in a social context. In: Berkman L, Kawachi I, editors. Social epidemiology. New York, New York: Oxford University Press; 2003;242-266.

19. Morgan DL. Quota sampling. In: Given LM, editor. The Sage encyclopedia of qualitative research methods. Thousand Oaks, CA: Sage; 2008;723-724.

20. O'Donnell DE, Aaron S, Bourbeau J, Hernandez P, Marciniuk DD, Balter M, et al. Canadian Thoracic Society recommendations for management of chronic obstructive pulmonary disease-2007 update. Can Respir J 2007;14(Suppl B):5B-32B.

21. Patton MQ. Qualitative research \& evaluation methods, 3rd edition. Thousand Oaks, CA: Sage Publications; 2001.

22. Braun V, Clarke V. Using thematic analysis in psychology. Qual Res Psychol 2006;3(2):77-101.

23. Glaser BG, Strauss AL. The discovery of grounded theory: strategies for qualitative research. Chicago, IL: Aldine Publishing; 1967.

24. McAuley E. Self-efficacy and the maintenance of exercise participation in older adults. J Behav Med 1993;16(1):103-113.

25. Petter M, Blanchard C, Kemp KA, Mazoff AS, Ferrier SN. Correlates of exercise among coronary heart disease patients: review, implications and future directions. Eur J Cardiovasc Prev Rehabil 2009; 16(5):515-526.

26. Wilcox S, Oberrecht L, Bopp M, Kammermann SK, McElmurray CT. A qualitative study of exercise in older African American and white women in rural South Carolina: perceptions, barriers, and motivations. J Women Aging 2005;17(1-2):37-53.

27. Witcher CSG, Holt NL, Spence JC, Cousins SO. A case study of physical activity among older adults in rural Newfoundland, Canada. J Aging Phys Act 2007;15(2):166-183.

28. Cooper AF, Jackson G, Weinman J, Horne R. A qualitative study investigating patients' beliefs about cardiac rehabilitation. Clin Rehabil 2005;19(1):87-96

29. Bandura A. Self-efficacy: toward a unifying theory of behavioural change. Psychol Rev 1977;84(2):191-215.

30. Wise JB, Trunnell EP. The influence of self-efficacy upon efficacy strength. J Sport Exerc Psychol 2001;23(4):268-280.

31. Hogg L, Grant A, Garrod R, Fiddler H. People with COPD perceive ongoing, structured and socially supportive exercise opportunities to be important for maintaining and active lifestyle following pulmo- nary rehabilitation: a qualitative study. J Physiother 2012;58(3):189195.

32. Aryal S, Diaz-Guzman E, Mannino DM. COPD and gender differences: an update. Transl Res 2013;162(4):208-218.

33. Robles PG, Brooks D, Goldstein R, Salbach N, Mathur S. Genderassociated differences in pulmonary rehabilitation outcomes in people with chronic obstructive pulmonary disease: a systematic review. J Cardiopulm Rehabil Prev 2014;34(2):87-97.

34. Spence JC, Blanchard CM, Clark M, Plotnikoff RC, Storey KE, McCargar L. The role of self-efficacy in explaining gender differences in physical activity among adolescents: a multilevel analysis. J Phys Act Health 2010;7(2):176-183.

35. Troiano RP, Berrigan D, Dodd KW, Mâsse LC, Tilert T, McDowell M. Physical activity in the United States measured by accelerometer. Med Sci Sports Exerc 2008;40(1):181-188.

36. Trost SG, Owen N, Bauman AE, Sallis JF, Brown W. Correlates of adults' participation in physical activity: review and update. Med Sci Sports Exerc 2002;34(12):1996-2001.

37. Colley RC, Garriguet D, Janssen I, Craig CL, Clarke J, Tremblay MS. Physical activity of Canadian adults: accelerometer results from the 2007 to 2009 Canadian health measures survey. Health Rep 2011;22(1):7-14

38. Bottorff JL, Oliffe JL, Kelly M. The gender(s) in the room. Qual Health Res 2012;22(4):435-440.

39. Allen JK, Scott LB, Stewart KJ, Young DR. Disparities in women's referral to and enrollment in outpatient cardiac rehabilitation. J Gen Intern Med 2004;19(7):747-753.

40. Boutin-Foster C. Getting to the heart of social support: a qualitative analysis of the types of instrumental support that are most helpful in motivating cardiac risk factor modification. Heart Lung 2005;34(1): 22-29.

41. McGannon KR, Busanich R, Witcher CSG, Schinke RJ. A social ecological exploration of physical activity influences among rural men and women across life stages. Qual Res Sport Exerc Health 2014;6(4):517-536.

42. Joo MJ, Sharp LK, Au DH, Lee TA, Fitzgibbon ML. Use of spirometry in the diagnosis of COPD: a qualitative study in primary care. COPD 2013;10(4):444-449. 